\title{
Endocrine Precursor Lesions and Microadenomas of the Duodenum and Pancreas with and without MEN1: Criteria, Molecular Concepts and Clinical Significance
}

\author{
Martin Anlauf $^{a} \quad$ Aurel Perren $^{b, c}$ Günter Klöppel ${ }^{a}$ \\ ${ }^{a}$ Department of Pathology, University of Kiel, Kiel, and b ${ }^{b}$ Department of Pathology, Technical University of \\ München, München, Germany; ' Department of Pathology, University Hospital of Zürich, Zürich, Switzerland
}

\begin{abstract}
Key Words
Endocrine tumor - Gastrinoma - MEN1 mutation • Insulinoma $\cdot$ Zollinger-Ellison syndrome
\end{abstract}

\begin{abstract}
Proliferative changes in the neuroendocrine cells that precede neoplasia are of interest for the understanding of tumorigenesis and the early recognition of neuroendocrine tumors. This review focuses on precursor lesions of duodenal and pancreatic neuroendocrine tumors in multiple endocrine neoplasia type 1 (MEN1) and also discusses 2 new disease entities of pancreatic microadenomatosis. The gastrinomas observed in MEN1 are almost exclusively localized in the duodenum and are multicentric. It has been shown that, in contrast to sporadic duodenal gastrinomas, they are associated with hyperplastic gastrin cell lesions and tiny gastrin-producing microtumors less than $500 \mu \mathrm{m}$ in diameter. In the pancreas, microadenomatosis (multiple tumors up to $5 \mathrm{~mm}$ in diameter) is a feature of MEN1. These microadenomas predominantly express glucagon and pancreatic polypeptide, but do not cause a hormonal syndrome. Approximately $50 \%$ of MEN1 minigastrinomas in the duodenum and almost all microadenomas in the pancreas show allelic deletion of the MEN1 gene and therefore may represent 'initial' neoplasms. In contrast, endocrine cell precursor lesions retain heterozygosity. Pancreatic microadenomatosis was also found unassociated with hereditary syndromes and 2 mono-
\end{abstract}

hormonal types were identified: (1) glucagon-producing microadenomatosis and (2) insulin-producing microadenomatosis, both associated with macrotumors. Whether these types of microadenomatosis represent novel disease entities and how to diagnose and treat these patients remains to be clarified by further studies. Copyright $\odot 2007$ S. Karger AG, Basel

\section{Introduction}

For diagnosis and therapy, as well as for the understanding of the tumorigenesis of malignant tumors, the identification of lesions that precede neoplastic growth and may represent a sequence of cellular changes from hyperplasia to neoplasia is of great interest.

There are some endocrine tumors, such as medullary thyroid carcinoma or pheochromocytoma, that develop on the basis of hyperplastic changes [1-2]. Furthermore, it is likely that the adenomatous changes of the parathyroid in multiple endocrine neoplasia type 1 (MEN1) patients originate from hyperplastic changes. All such conditions, except for enterochromaffin-like cell hyperplasia in chronic atrophic gastritis, are associated with an inherited endocrine disorder [3-5].

This review focuses on endocrine precursor lesions and microadenomatosis in the duodenum and pancreas of patients with MEN1. Molecular concepts and potential

\section{KARGER}

Fax +4161306 1234

E-Mail karger@karger.ch

www.karger.com (c) 2007 S. Karger AG, Basel

$1015-2008 / 07 / 0745-0279 \$ 23.50 / 0$

Accessible online at:

www.karger.com/pat
Martin Anlauf, MD

Department of Pathology, University of Kiel

Michaelisstrasse 11

DE-24105 Kiel (Germany)

Tel. +49 431597 1138, Fax +49 431597 3462, E-Mail manlauf@path.uni-kiel.de 
clinical significance are discussed. In addition, 2 new disease entities are presented. Both are characterized by non-MEN1-associated microadenomatosis of the pancreas, but one shows glucagon-producing tumors, while the other displays multiple insulinomas.

\section{Duodenum}

Gastrin-producing tumors are the most common type of neuroendocrine tumor (NET) in the duodenum [6-8]. Most of them are associated with a Zollinger-Ellison syndrome (ZES) characterized by elevated fasting gastrin serum levels, a positive gastrin secretin stimulation test and clinical symptoms such as recurrent peptic ulcer disease, gastroesophageal reflux disease and, occasionally, diarrhea [9]. Though duodenal gastrinomas are often small in size (diameter less than $1 \mathrm{~cm}$ ), they tend to metastasize early to regional lymph nodes and the liver $[10,11]$. Surgical treatment of sporadic gastrinomas by local excision and lymphadenectomy is in many cases curative, while the same procedure usually does not cure patients with MEN1-associated duodenal gastrinomas [10].

In 1990 it was noticed that many duodenal gastrinomas arising in the setting of MEN1 are multiple, in contrast to sporadic gastrinomas [12]. Recently, it has been shown that in addition to gastrinomas, somatostatinproducing tumors can also arise in the duodenum of patients with MEN1. These multicentric gastrin- and somatostatin-producing NETs were found to be associated with gastrin and somatostatin cell precursor lesions within the nontumorous duodenal mucosa [11], whose spectrum of proliferative changes was similar to that described for enterochromaffin-like cells in chronic atrophic fundus gastritis [13]. Therefore, an analogous classification has been proposed (table 1) that distinguishes between diffuse, linear and micronodular hyperplasia of gastrin cells associated either with the crypts or with Brunner's glands (fig. 1). Lesions more than $300 \mu \mathrm{m}$ in size, which were encountered less frequently than the hyperplastic changes, were classified as microtumors (fig. 2). The proliferative nature of these lesions was confirmed by enhanced Ki-67 expression, contrasting with the lack of Ki-67 expression in nonhyperplastic gastrin cells. The hyperproliferative and hyperplastic lesions were found in all patients with MEN1 but were absent in patients with sporadic (non-MEN1-associated) duodenal gastrinomas and ZES. Because of the smooth transition from hyperplastic to early neoplastic gastrin cell lesions, these alterations were considered to be precursor lesions
Table 1. Classification of proliferative gastrin cell lesions in the duodenum of patients with MEN1

\begin{tabular}{ll}
\hline Pattern & Definition \\
\hline $\begin{array}{l}\text { Diffuse } \\
\text { hyperplasia }\end{array}$ & $\begin{array}{l}\text { increase in single gastrin-positive cells } \\
\text { (confirmed by morphometric analysis) }\end{array}$ \\
\hline $\begin{array}{l}\text { Linear } \\
\text { hyperplasia }\end{array}$ & $\begin{array}{l}\text { formation of chains of } \geq 5 \text { gastrin-positive } \\
\text { cells and } \geq 2 \text { chains per mm }\end{array}$ \\
\hline $\begin{array}{l}\text { Micronodular } \\
\text { hyperplasia }\end{array}$ & $\begin{array}{l}\text { nodules of gastrin-positive cells with } \\
>5 \text { gastrin-positive cells within glands or crypt } \\
(30-90 \mu m)\end{array}$ \\
\hline Enlarged nodule & $\begin{array}{l}\text { nodules of gastrin-positive cells with solid } \\
\text { architecture }(\geq 90 \text { to }<210 \mu m)\end{array}$ \\
\hline $\begin{array}{l}\text { Microinvasive } \\
\text { lesion }\end{array}$ & $\begin{array}{l}\text { small clusters of gastrin-positive cells localized } \\
\text { in the lamina propria between the glands and } \\
\text { surrounded by thickened collagen }\end{array}$ \\
\hline Microtumor & $\begin{array}{l}\text { tumorous lesion with trabecular growth } \\
\text { pattern and extensive fibrosis } \\
\text { (diameter }>250 \mu m)\end{array}$ \\
\hline
\end{tabular}

of the MEN1-associated duodenal gastrinomas. The fact that such gastrin cell hyperplasia occurred at various sites in the duodenal mucosa explains the multifocality of MEN1 gastrinomas and the failure to cure patients with MEN1-associated ZES by simple tumor excision.

Tumor precursor lesions are assumed to show a sequence of genetic changes that lead to overt neoplasia. In MEN1 patients, all somatic cells harbor a germline mutation of the MEN1 gene, which is considered to be a tumor suppressor gene $[5,14,15]$. Recently, a loss of heterozygosity $(\mathrm{LOH})$ of the MEN1 gene and/or the centromere 11 was demonstrated in approximately $50 \%$ of MEN1-associated duodenal NETs [16]. Allelic loss was detected in tumors as small as $300 \mu \mathrm{m}$ (gastrin) and $400 \mu \mathrm{m}$ (somatostatin) in diameter. In contrast to tumors, the hyperplastic gastrin and somatostatin cells consistently lacked LOH on chromosome 11q13. This finding suggested that though the hyperplastic cells were hyperproliferative and carried the MEN1 germline mutation, they had not yet assumed the neoplastic genotype characterized by the allelic loss of 11q13. We do not know what mechanisms enhance the proliferation of gastrin cells and produce hyperplasia, but they could be related to an increased responsiveness of the gastrin cell bearing the germ cell MEN1 mutation to certain growth factors.

In conclusion, allelic deletion of the second MEN1 gene seems to be a pivotal event in the development of 
Fig. 1. MEN1-associated circumscript diffuse hyperplasia of gastrin-expressing endocrine cells within the duodenal Brunner's glands.

Fig. 2. MEN1-associated gastrin-expressing microadenoma of less than $1 \mathrm{~mm}$ in diameter at the top of a duodenal villus.
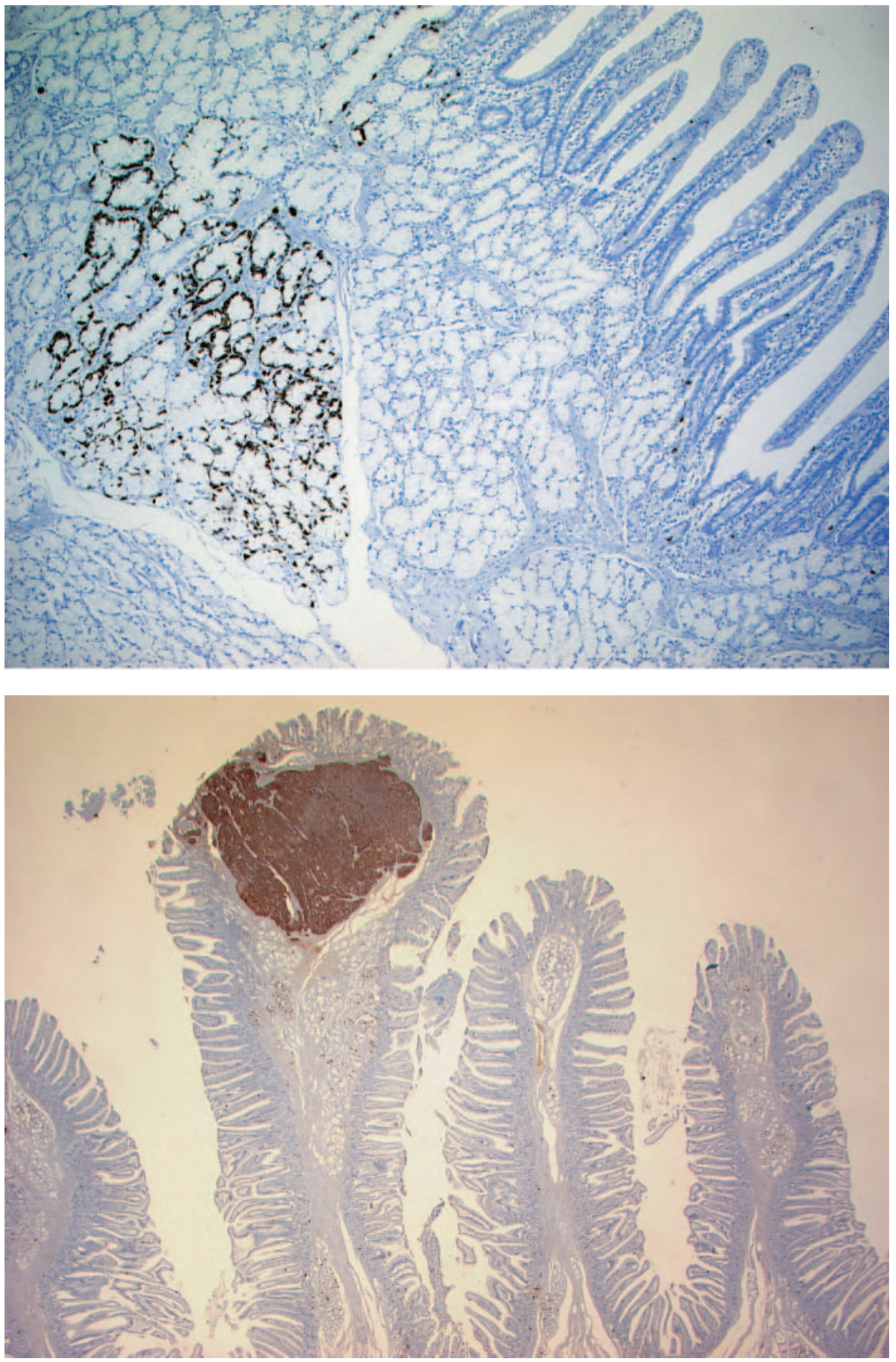

multifocal gastrin and somatostatin cell neoplasms in the duodenum of MEN1 patients. The observation of distinct deletion patterns in the synchronous MEN1 tumors supports the concept that each gastrin-producing tumor in an individual MEN1 patient arises from an independent cell clone.

\section{Pancreas}

Most pancreatic NETs are sporadic tumors. Approximately $10 \%$ of pancreatic NETs arise in patients with a hereditary background of MEN1 $[5,15]$. The presence of multiple small endocrine tumors in the pancreas (i.e. up 
Fig. 3. MEN1-associated pancreatic microadenoma of less than $1 \mathrm{~mm}$ in size.

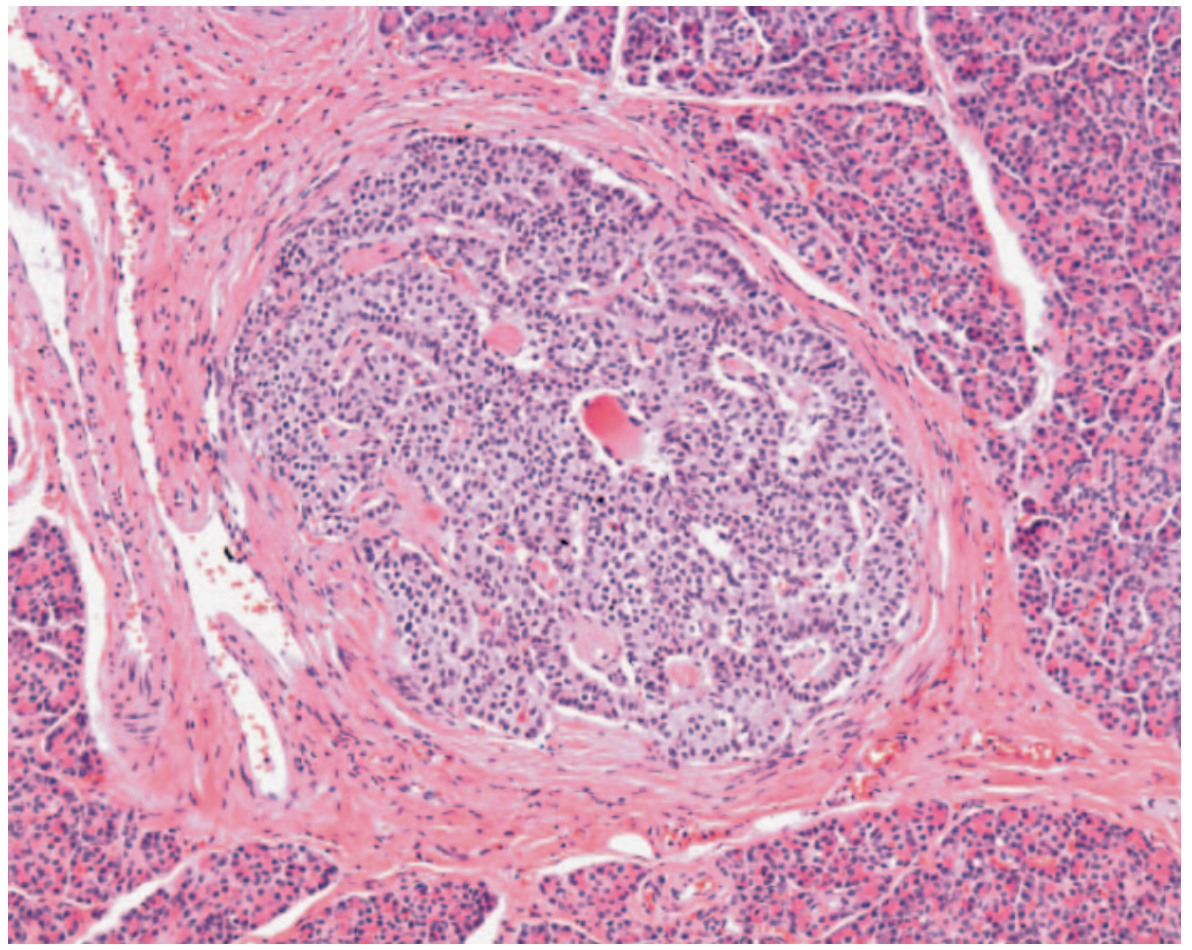

to $5 \mathrm{~mm}$ in diameter) has been referred to as microadenomatosis and has been described in association with the MEN1 syndrome [17]. MEN1-associated pancreatic microadenomatosis is usually accompanied by 1 or more macrotumors (diameter $>5 \mathrm{~mm}$ ), some of which may be functionally active $[15,16,18]$.

Although the identification of the MEN1 gene on $11 \mathrm{q} 13$ has led to extensive studies of the genetic and clinical features of the MEN1 syndrome, our knowledge of the development and pathology of pancreatic endocrine neoplasms in MEN1 is mainly based on reports of individual cases. Only few studies on a series of MEN1 patients have been published $[17,18]$. In a recent study by our group we analyzed pancreatic specimens from 28 MEN1 patients [19]. Previous studies showed that microadenomatosis in MEN1 patients is highly variable as far as the number of tumors and their hormonal profiles are concerned [17-20]. We confirmed these observations and established a high penetrance for pancreatic microadenomatosis $(>80 \%)$ in MEN1 patients. The hormone-positive microadenomas were usually multihormonal, with glucagon as the predominant hormone (fig. 3). Although many patients had numerous microadenomas, they did not appear to be associated with a hormonal syndrome. If symptoms of inappropriate hormone secretion, such as persistent hyperinsulinemic hypoglycemia, were present, they could be related to 1 or more insulin-producing macrotumors ( $>5 \mathrm{~mm}$ ).

As tiny as the pancreatic microadenomas in MEN1 were (i.e. less than $200 \mu \mathrm{m}$ ), they showed the signs of neoplastic tumors: (1) monohormonality, (2) trabecular growth pattern and (3) a distinct stromal component [1718]. Furthermore, Vortmeyer et al. [21] and we [22] demonstrated LOH of the MEN1 gene locus in MEN1-associated pancreatic microadenomas.

Opinions vary as to which type of endocrine cell lesion precedes the development of microadenomas in patients with MEN1. Recently, Vortmeyer et al. [21] found 11q13 $\mathrm{LOH}$ in duct-associated lesions but not in islets and their conclusion was that there is a 'non-islet cell origin of pancreatic islet cell tumors'. In our study, using a technique combining fluorescence in situ hybridization of the MEN1 locus and the centromeric region of chromosome 11q with hormone immunostaining, we found loss of one MEN1 allele in all microadenomas and in 19 of 20 monohormonal endocrine cell clusters examined. By contrast, $\mathrm{LOH}$ on $11 \mathrm{q}$ was absent in islets and ductal or acinar structures. Our results indicate that monohormonal endocrine cell clusters represent a minute form of microadenomas. The frequent presence of single nonneoplastic 
insulin cells in microadenomas and the occurrence of monohormonal endocrine cell clusters intermingled with islets suggest an islet origin of microadenomas rather than a non-islet origin.

\section{Non-MEN1-Related Microadenomatosis of the Pancreas}

Microadenomatosis of the endocrine pancreas has been described in a single case report of a patient with Von Hippel-Lindau (VHL) syndrome [23]. In contrast, in a study by Lubensky et al. [24], the smallest tumor encountered in a series of $30 \mathrm{VHL}$-associated pancreatic NETs was $0.4 \mathrm{~cm}$ in diameter, but microadenomatosis was not described in any of their cases. We screened the clinicopathological records of 425 patients suffering from pancreatic NETs [19] and found only 2 who fulfilled the criteria of a VHL syndrome. The 2 patients exhibited solitary functionally inactive clear cell NETs without associated microadenomatosis. These observations do not exclude the possibility that microadenomatosis is a feature of VHL-associated pancreatic NETs, but might suggest that the frequency of this feature is lower than in MEN1.

A special finding was the identification of pancreatic microadenomatosis in 9 patients who had multiple microadenomas but neither clinical nor genetic features of the MEN1 or VHL syndrome. Five of these 9 patients suffered from hyperinsulinemic hypoglycemia and, in addition to insulin-positive microadenomas, had insulinpositive macrotumors. Two of the 5 patients with hyperinsulinemic hypoglycemia had only insulin-positive microadenomas, most of which were less than $1 \mathrm{~mm}$ in diameter. Four other patients had multiple small glucagon-expressing neoplasms, 3 of them with additional macrotumors. None of the 4 patients with multiple glucagon-producing NETs showed clinical signs of a glucagonoma syndrome. This observation suggests that what we encountered are 2 new disease entities characterized by pancreatic endocrine microadenomatosis; one causing hyperinsulinemic hypoglycemia, the other without any clinical syndrome but numerous glucagon-producing tumors. The mechanisms that may cause microadenomatosis in these patients are as yet unknown.

\section{Summary and Conclusions}

MEN1-associated duodenal gastrinomas and somatostatinomas are preceded by hyperplastic gastrin and somatostatin cell changes as well as tiny gastrin or somatostatin-producing neoplasms less than $400 \mu \mathrm{m}$ in diameter.

Allelic deletion of the MEN1 gene in microadenomas but not in hyperplastic lesions may reflect a pivotal genetic event in the development of multifocal gastrin and somatostatin cell neoplasms in the duodenum of MEN1 patients.

The observation of distinct deletion patterns in very small synchronous tumors supports the concept that each gastrin- and somatostatin-producing tumor in an individual MEN1 patient arises from an independent cell clone.

Sporadic (non-MEN1-associated) duodenal gastrinomas lack evidence of precursor lesions.

Endocrine microadenomatosis of the pancreas is a MEN1-associated feature of high penetrance. The microadenomas in MEN1 are characterized by the frequent expression of glucagon. They are most likely not able to cause a hormonal syndrome.

Almost all pancreatic microadenomas show allelic deletion of the MEN1 gene and may therefore represent true 'initial' neoplasms.

Monohormonal endocrine cell clusters show a high frequency of LOH of the MEN1 allele and therefore represent a minute form of microadenoma.

The frequent presence of single nonneoplastic insulin cells in microadenomas and the occurrence of microadenomas in islets suggest an islet origin of microadenomas.

Two types of pancreatic microadenomatosis without any hereditary background were identified that were characterized either by multiple hormonally silent glucagon-producing tumors or multiple syndromatic insulinproducing tumors.

\section{Acknowledgements}

We thank Regina Schlenger, Tobias Henopp, Anja Schmitt, Juliane Bauersfeld, Nele Garbrecht, Tetsuji Enosawa, Marie L. Kruse, Eberhard Weihe, Markus Krausch, Andreas Raffel, Oliver Gimm, Anne Couvelard, Philippe Ruszniewski, Christian A. Koch, Wolfram T. Knoefel, Henning Dralle, Philipp U. Heitz and Paul Komminoth for their extensive support to analyze tissues of patients with multiple endocrine tumor diseases of the duodenum and pancreas. The projects summarized were approved by the Ethics Committee of the University of Kiel (D430/2005).

This work was supported by the Hensel Stiftung Kiel (F370011; M.A. and G.K.), the Swiss National Foundation (SNF 31-61884; A.P.), the German Society of Pathology (M.A.) and Novartis Oncology, Nürnberg, Germany. 


\section{References}

$>1$ Huang SC, Koch CA, Vortmeyer AO, Pack SD, Lichtenauer UD, Mannan P, Lubensky IA, Chrousos GP, Gagel RF, Pacak K, Zhuang Z: Duplication of the mutant RET allele in trisomy 10 or loss of the wild-type allele in multiple endocrine neoplasia type 2 -associated pheochromocytomas. Cancer Res 2000; 60:6223-6226

$>2$ Koch CA, Huang SC, Moley JF, Azumi N, Chrousos GP, Gagel RF, Zhuang Z, Pacak K, Vortmeyer AO: Allelic imbalance of the mutant and wild-type RET allele in MEN 2A-associated medullary thyroid carcinoma. Oncogene 2001;20:7809-7811.

$\checkmark 3$ Solcia E, Bordi C, Creutzfeldt W, et al: Histopathological classification of nonantral gastric endocrine growths in man. Digestion 1988;41:185-200.

4 Studer H, Derwahl M: Mechanisms of nonneoplastic endocrine hyperplasia - a changing concept: a review focused on the thyroid gland. Endocr Rev 1995;16:411-426.

$\checkmark 5$ Marx SJ, Simonds WF: Hereditary hormone excess: genes, molecular pathways, and syndromes. Endocr Rev 2005;26:615-661.

$\checkmark 6$ Burke AP, Federspiel BH, Sobin LH, Shekitka KM, Helwig EB: Carcinoids of the duodenum: a histologic and immunohistochemical study of 65 tumors. Am J Surg Pathol 1989;13:828-837.

7 Capella C, Riva C, Rindi G, et al: Histopathology, hormone products, and clinicopathological profile of endocrine tumors of the upper small intestine: a study of 44 cases. Endocr Pathol 1991;2:92-110.

$>8$ Anlauf M, Garbrecht N, Henopp T, et al: Sporadic versus hereditary gastrinomas of the duodenum and pancreas: distinct clinicopathological and epidemiological features. World J Gastroenterol 2006;12:5440-5446.
9 Zollinger RM, Ellison EH: Primary peptic ulcerations of the jejunum associated with islet cell tumors of the pancreas. Ann Surg 1955;142:709-723.

10 Norton JA, Fraker DL, Alexander HR, et al: Surgery to cure the Zollinger-Ellison syndrome. N Engl J Med 1999;341:635-644.

11 Anlauf M, Perren A, Meyer CL, et al: Precursor lesions in patients with multiple endocrine neoplasia type 1-associated duodenal gastrinomas. Gastroenterology 2005;128: 1187-1198.

12 Pipeleers-Marichal M, Somers G, Willems $\mathrm{G}$, et al: Gastrinomas in the duodenums of patients with multiple endocrine neoplasia type 1 and the Zollinger-Ellison syndrome. N Engl J Med 1990;322:723-727.

13 Solcia E, Capella C, Fiocca R, Cornaggia M, Bosi F: The gastroenteropancreatic endocrine system and related tumors. Gastroenterol Clin North Am 1989;18:671-693.

14 Chandrasekharappa SC, Guru SC, Manickam $\mathrm{P}$, et al: Positional cloning of the gene for multiple endocrine neoplasia-type 1 . Science 1997;276:404-407.

15 Calender A, Morrison CD, Komminoth P, Scoazec JY, Sweet KM, Teh BT: Multiple endocrine neoplasia type 1; in DeLellis RA, Lloyd RV, Heitz PU, Eng C (eds): Pathology and Genetics: Tumours of Endocrine Organs. WHO Classification of Tumors. Lyon, IARC Press, 2004, pp 218-227.

16 Anlauf M, Perren A, Henopp T, et al: Allelic deletion of the MEN1 gene in duodenal gastrin and somatostatin cell neoplasms and their precursor lesions. Gut 2007;56:637644.
17 Klöppel G, Willemer S, Stamm B, Häcki WH, Heitz PU: Pancreatic lesions and hormonal profile of pancreatic tumors in multiple endocrine neoplasia type I: an immunocytochemical study of nine patients. Cancer 1986;57:1824-1832.

18 Thompson NW, Lloyd RV, Nishiyama RH, et al: MEN 1 pancreas: a histological and immunohistochemical study. World J Surg 1984;8:561-574.

19 Anlauf M, Schlenger R, Perren A, et al: Microadenomatosis of the endocrine pancreas in patients with and without the multiple endocrine neoplasia type 1 syndrome. Am J Surg Pathol 2006;30:560-574.

20 Le Bodic MF, Heymann MF, Lecomte M, et al: Immunohistochemical study of 100 pancreatic tumors in 28 patients with multiple endocrine neoplasia, type I. Am J Surg Pathol 1996;20:1378-1384

-21 Vortmeyer AO, Huang S, Lubensky I, Zhuang $\mathrm{Z}$ : Non-islet origin of pancreatic islet cell tumors. J Clin Endocrinol Metab 2004;89: 1934-1938.

22 Perren A, Anlauf M, Henopp T, et al: Multiple endocrine neoplasia type 1: loss of one MEN1 allele in tumors and monohormonal endocrine cell clusters, but not in islet hyperplasia of the pancreas: a combined FISH and immunofluorescence study. J Clin Endocrinol Metab 2006, E-pub ahead of print.

23 Chetty R, Kennedy M, Ezzat S, Asa SL: Pancreatic endocrine pathology in von HippelLindau disease: an expanding spectrum of lesions. Endocr Pathol 2004;15:141-148.

24 Lubensky IA, Pack S, Ault D, et al: Multiple neuroendocrine tumors of the pancreas in von Hippel-Lindau disease patients: histopathological and molecular genetic analysis. Am J Pathol 1998;153:223-231. 